\title{
RELAÇÕES FEDERATIVAS NO FINANCIAMENTO DA EDUCAÇÃO NO BRASIL E NA ARGENTINA
}

\author{
RELACIONES FEDERATIVAS EN LA FINANCIACIÓN DE LA EDUCACIÓN EN \\ BRASIL Y EN ARGENTINA
}

\author{
FEDERATIVE RELATIONS ON THE FINANCING OF EDUCATION IN BRAZIL AND \\ ARGENTINA
}

\author{
Diego Dartagnan da Silva TORMES ${ }^{1}$ \\ Nalú FARENZENA ${ }^{2}$
}

RESUMO: O artigo apresenta resultados parciais de uma pesquisa de cunho comparativo que objetiva discutir o federalismo como forma de organização do Estado e suas repercussões para a organização e o financiamento da educação básica na Argentina e no Brasil. Foi utilizada a metodologia de análise documental com especial atenção aos documentos legais que organizam e regulam as relações federativas na educação e no financiamento da educação nos dois países. Como principais achados tem-se o fato de que a oferta e o financiamento da educação básica estão descentralizados, sob responsabilidade acentuada dos entes subnacionais, ainda que existam mecanismos de atuação do ente nacional no financiamento da educação, seja repartindo recursos ou atuando de forma complementar.

PALAVRAS-CHAVE: Federalismo. Financiamento da educação. Relações federativas na educação.

RESUMEN: El artigo presenta resultados parciales de una pesquisa comparativa que tiene como objetivo discutir sobre el federalismo como forma de organización del Estado y sus consecuencias para la organización del financiamiento de la educación básica en la Argentina y Brasil. Fue utilizada la metodología de análisis documental en especial a los documentos legales que organizan y regulan las relaciones federativas en la educación y en el financiamiento de la educación en los dos países. Como principales resultados se percibió que la oferta y el financiamiento de la educación básica están descentralizados y a cargo de los entes subnacionales, aunque existan mecanismos de actuación del ente nacional en el financiamiento de la educación, sea repartiendo ingresos de impuestos o complementando el financiamiento cuando necesario.

PALABRAS CLAVE: Federalismo. Financiación de la educación. Relaciones federativas en la educación.

\footnotetext{
${ }^{1}$ Universidade Federal do Rio Grande do Sul (UFRGS), Porto Alegre - RS - Brasil. Discente do Programa de Pós-Graduação em Educação. ORCID: https://orcid.org/0000-0003-1900-7731. E-mail: diegotormes2@gmail.com

${ }^{2}$ Universidade Federal do Rio Grande do Sul (UFRGS), Porto Alegre - RS - Brasil. Professora titular. Integrante do Núcleo de Estudos de Política e Gestão da Educação da UFRGS. ORCID: https://orcid.org/0000-0003-25825925. E-mail: nalu.farenzena@gmail.com
}

RIAEE - Revista Ibero-Americana de Estudos em Educação, v. 14, n. esp. 3, p. 1688-1701, out., 2019. 
ABSTRACT: The article presents partial results of a comparative research that aims to discuss federalism as a form of organization of the State and its repercussions for the organization and financing of basic education in Argentina and Brazil. Documentary analysis methodology was used and special attention was given to the legal documents that organize and regulate the federative relations in education and in the financing of education in both countries. As the main findings are the fact that the supply and financing of basic education are decentralized, under the marked responsibility of the subnational ones, although there are mechanisms of action of the national one in the financing of education, either by repairing resources or acting in a complementary way.

KEYWORDS: Federalism. Financing of education. Federal relations in education.

\section{Introdução}

O presente texto contém resultados parciais de uma pesquisa sobre as relações entre a organização federativa do Estado e o financiamento da educação no Brasil e na Argentina, desenvolvida no âmbito de estudos de Doutorado em Educação ${ }^{3}$. A pesquisa é desenvolvida por meio de revisão de bibliografia e de análise documental, em especial de documentos legais. O recorte aqui realizado contempla a compreensão do federalismo como forma de organização do Estado, seus principais modelos, e suas influências para a organização e o financiamento da educação básica na Argentina e no Brasil.

O texto está dividido em cinco capítulos, incluindo esta introdução. No segundo capítulo são trabalhados conceitos e modelos de federalismo, bem como as opções federativas do Brasil e da Argentina. Em seguida são analisados os principais aspectos legais referentes à organização da educação nos dois países selecionados, especificamente, a repartição de competências na oferta, articulações federativas e mecanismos de financiamento. No quarto capítulo são delineadas algumas aproximações e distanciamentos entre os dois sistemas federativos, especificamente nos aspectos relativos ao financiamento da educação.

\section{Federalismo e relações federativas}

Brasil e Argentina são os países foco desse estudo pois, além de fazerem parte do mesmo continente e bloco econômico, qual seja, o Mercado Comum do Sul (MERCOSUL), possuem semelhante organização política e administrativa do Estado, definida em suas constituições:

${ }^{3} \mathrm{O}$ autor deste artigo é doutorando do Programa de Pós-Graduação em Educação da Universidade Federal do Rio Grande do Sul. A coautora orienta os estudos do autor e desenvolveu, entre 2014 e 2018, estudo comparado sobre políticas de financiamento da educação na Argentina, Brasil e Uruguai (FARENZENA et al., 2018). 
organização federativa. O conceito de federalismo tem sido abordado por diversos pesquisadores como um modo de organização do Estado e distribuição do poder dentro dele. Tratando-se de divisão de poder e responsabilidades entre um ente central e demais entes periféricos, constitui-se, na prática, como elemento de coordenação política em um determinado território, a partir do qual, segundo Ventura (2002), o princípio federal pressupõe que unidades territoriais autônomas (províncias, estados, länder, municípios, regiões administrativas, distritos, oblasts) entrem em uma união duradoura com objetivos comuns, união que tem relação com a origem etimológica do termo foedus, que significa pacto, aliança ou tratado. Segundo a organização não governamental Forum of Federations ${ }^{4}$ existem, na atualidade, aproximadamente 25 países que se organizam de forma federativa, desde países pequenos como a Bélgica até gigantes como a Rússia. No caso do continente americano os países que adotam uma organização federativa são: Argentina, Brasil, Canadá, Estados Unidos da América, México e Venezuela.

Abruccio (2010) define federalismo como forma de organização territorial do Estado na qual os governos subnacionais têm autonomia e compartilham a legitimidade do poder e do processo decisório. Os diferentes entes federados, em um território, possuem o poder dividido entre eles de forma que todos possam participar, dentro de regras pré-estabelecidas, das decisões políticas e administrativas, convertendo-se em mecanismo político de unidade com respeito às diversidades econômicas, culturais, geográficas ou históricas. Para que haja uma federação, apesar da autonomia e liberdade dos entes subnacionais, todos eles devem estar regidos juridicamente sob o mesmo ordenamento constitucional. Aqui é preciso um cuidado para não confundir a autonomia dos entes subnacionais com soberania. A primeira diz respeito ao poder e responsabilidade atribuídos a cada um dos entes federados e a segunda é conferida à nação, que deve exercê-la dentro dos limites constitucionais. Nesse sentido, o federalismo torna-se a união política de coletividades e diversidades regionais que, através de sua autonomia, participam das decisões e compartilham o poder até o limite da soberania estabelecido na constituição.

Considerando a variedade de países que adotam o modelo federativo de organização do Estado, alguns autores, como Ventura (2002), Martins (2011), Abruccio (2010), Oliveira (2007) e Bobbio (2010) mencionam diferentes tipos de federalismo encontrados pelo mundo, muito

${ }^{4}$ Organização não governamental que engloba diversos países que adotam a forma federada de Estado e atua no desenvolvimento e divulgação de estudos sobre a prática da governança federal e descentralizada. 
relacionados às questões históricas, culturais, políticas e geopolíticas de cada país. Há certo consenso em categorizar os tipos de federalismo, conforme apresentado no Quadro 1.

Quadro 1 - Modelos de federalismo

\begin{tabular}{|l|l|}
\hline Modelo & Características \\
\hline Centrípeto & $\begin{array}{l}\text { Ocorre quando os poderes se concentram mais no ente nacional e menos } \\
\text { nos entes subnacionais. }\end{array}$ \\
\hline Centrífugo & $\begin{array}{l}\text { Ocorre quando se distribui poder aos entes subnacionais, consagrando } \\
\text { mecanismos de descentralização. }\end{array}$ \\
\hline Equilíbrio & $\begin{array}{l}\text { Ocorre quando os mecanismos jurídicos e constitucionais buscam } \\
\text { equilibrar as relações entre o ente nacional e os demais entes federados. }\end{array}$ \\
\hline
\end{tabular}

Fonte: Elaborado pelos autores com base em Martins (2011), Abruccio (2010), Oliveira (2007) e Bobbio (2010).

Além dessas características elencadas acima, segundo Ventura (2000), ao analisar aspectos teóricos do federalismo em relação à construção histórica do mesmo em diversos países, é possível também falar em federalismo dual (com disputa de força e equilíbrio entre o poder central e periférico) e federalismo cooperativo (a disputa é substituída por mecanismos jurídicos institucionais de cooperação entre o poder central e periférico). A mesma autora recorda que a definição primeira e mais clássica de federalismo se relaciona com a distribuição de competências dentro do Estado e está dividida entre federalismo vertical e horizontal. No caso de o Estado ter uma construção federativa vertical, todos os entes têm responsabilidades próprias e independentes, desde legislar até executar políticas públicas. No caso da organização federativa horizontal, ao contrário, há responsabilidades que são exclusivas dos entes federados subnacionais e outras que são do nível superior, o qual, no Brasil, é a União e, na Argentina, $L a$ Nación.

A respeito da organização federativa na contemporaneidade, a autora menciona que, após a segunda guerra mundial, houve uma ampliação das regulações dos estados nos aspectos econômicos e sociais, o que, desde uma perspectiva institucional, potencializou o papel do poder executivo, ampliando a necessidade de estruturas e mecanismos federativos (Ventura, 2000). Nesse sentindo explica que:

Nello Stato conteporaneo il federalismo si è trasformato da duale in cooperativo; la maggiore ingerenza statale ha portato ad una collaborazione 
sempre più stretta tra $i$ diversi livelli di governo, a prescendire dalle attribuizioni formali dele competenze (VENTURA, 2000, p. 28-29). ${ }^{5}$

Essa situação de existir uma necessidade contemporânea de um federalismo mais cooperativo, que se sustente em relações federativas de cunho mais solidário entre os entes federados, aplica-se, pelo menos desde uma perspectiva legal, à organização federativa do Brasil e da Argentina. Isso pois as constituições dos dois países os definirão como repúblicas que adotam a organização federada e, em função de diversos mecanismos explicitados nos textos respectivos textos constitucionais e infraconstitucionais, explicita-se a opção legal por um federalismo do tipo cooperativo entre o governo central e os demais entes da federação, como também, no caso brasileiro, entre estados e municípios.

A construção da opção federativa nos dois países se deu de maneiras bem distintas e surge no século XIX. No caso do Brasil, após a independência de Portugal, em 1822, a opção de manter o regime monárquico e a dinastia portuguesa comandando o país levou as autoridades, primeiro o Imperador Dom Pedro I e em seguida o Imperador Dom Pedro II, a manterem o território unido a partir da distribuição de títulos de nobreza para simpatizantes, membros do exército e da marinha ou ainda ricos produtores rurais do interior do país. A distribuição dessas honrarias tinha um preço: manter os longínquos territórios unidos no reino do Brasil. Embora constituído como Estado unitário durante os mais de sessenta anos de monarquia, houve movimentos no sentido de descentralização e de fortalecimento das competências legais e administrativas das províncias; a estrutura e a lógica federativas se instalam, porém, somente depois do golpe de Estado que instituiu a República, e mantém-se até hoje. No caso Argentino, após a independência da Espanha em 1816, diversos conflitos entre unitaristas e federais eclodiram. Os primeiros queriam uma organização centralizada com o poder residindo na cidade de Buenos Aires, os segundos defendiam uma organização mais federada com o poder dividido entre as províncias do interior e a província de Buenos Aires. Entre uma eleição e outra, várias batalhas armadas acabaram por definir a opção republicana e federativa do país.

O federalismo brasileiro se organiza, a partir da Constituição Federal de $1988^{6}$, com quatro entes federados (União, Distrito Federal, Estados e Municípios); já o federalismo

5 No Estado contemporâneo o federalismo transformou-se de dual para cooperativo, consequência da maior ingerência estatal que necessitou uma colaboração sempre mais próxima entre os diversos níveis de governo, independente das atribuições formais e das competências. (VENTURA, 2000, p. 28-29)

${ }^{6}$ Constituições anteriores (1891, 1934, 1937, 1946 e 1967) não colocavam os municípios como entes federados autônomos, fato esse que surgiu na década de oitenta, como forma de pressão por maior participação política democrática no período pós-ditatorial.

RIAEE - Revista Ibero-Americana de Estudos em Educação, v. 14, n. esp. 3, p. 1688-1701, out., 2019. 
argentino se organiza com três entes federados (la nación, províncias, Ciudad Autónoma de Buenos Aires) e, ainda que haja municípios, os mesmos têm sua autonomia, explicitada nas constituições das províncias, em geral ainda bem limitadas.

\section{Federalismo e educação}

O sistema educacional dos dois países também está organizado sob a lógica do federalismo a partir da repartição de competências entre os entes federados, no que diz respeito a diversas dimensões da atuação estatal, como a provisão de serviços (oferta), o financiamento, a normatização e o planejamento. Os principais aspectos da organização da educação estão estabelecidos nas respectivas constituições e em leis que regulam aspectos específicos do setor, como o financiamento, por exemplo. No caso brasileiro, a Constituição Federal de 1988 (CF/88) prevê a repartição de competências na oferta no seu artigo 211, bem como a responsabilidade de financiamento para cada ente federado no artigo 212. A Lei nº 9.394 de 1996, que estabelece as Diretrizes e Bases da Educação (LDB/96), em seus artigos $8^{\circ}, 9^{\circ}, 10^{\circ}$ e $11^{\circ}$ e $12^{\circ}$, reafirma a repartição de competências e de responsabilidades na oferta da educação e na garantia do direito à educação entre os entes federados. Em termos de competências na oferta da educação básica, cabe aos municípios, exclusivamente, a prioridade na oferta da educação infantil (seis anos de duração, para crianças de 0 a 5 anos de idade), aos estados e municípios, em regime de colaboração, a oferta do ensino fundamental (nove anos de duração), aos estados, em caráter quase exclusivo, a oferta de ensino médio (três anos de duração) e à União compete manter e administrar a rede pública federal ${ }^{7}$ e prestar assistência técnica e financeira aos estados e municípios, agindo supletivamente. A frequência à educação básica no Brasil é obrigatória para a população com idade entre quatro a dezessete anos, ou seja, da educação infantil/pré-escola ao ensino médio, totalizando quatorze anos de escolaridade.

No caso argentino, a federação conta com três entes federados: Nação, Cidade Autônoma de Buenos Aires (CABA) e as províncias, sendo que a oferta e gestão da educação é toda descentralizada para as províncias e a CABA. O sistema educacional compreende quatorze anos de escolarização obrigatória e está organizado em quatro níveis: a educação inicial (para crianças de 45 dias a cinco anos de idade); a educação primária, a partir dos seis anos de idade, com seis ou sete anos de duração, conforme opção de cada província; a educação secundária, para adolescentes e jovens que concluíram a educação primária, com cinco ou seis

${ }^{7}$ A rede pública federal é composta majoritariamente por instituições de educação superior.

RIAEE - Revista Ibero-Americana de Estudos em Educação, v. 14, n. esp. 3, p. 1688-1701, out., 2019. 
anos de duração, conforme opção de cada província. A lei $\mathrm{n}^{\circ}$. 26.206, Ley de Educación Nacional de 2006 (LEN), em seu artigo 43, menciona que as províncias e a CABA, na articulação de níveis de gestão e funções dos organismos competentes, estabelecerão procedimentos e recursos para identificar as necessidades para a sua aplicação. Essa lógica aparece também na Constituição, no artigo $5^{\circ}$, quando preceitua que cada província organize uma Constituição que assegure a administração da educação primária.

Alguns números da educação básica dos dois países encontram-se na Tabela 1.

Tabela 1 - Número de matrículas, escolas e professores na educação básica - Brasil e Argentina

\begin{tabular}{l|r|l|r}
\hline Indicador & \multicolumn{1}{|c|}{ Brasil $^{8}$} & Indicador & Argentina $^{9}$ \\
\hline Total de matrículas & 48.817 .479 & Total de matrículas & 12.536 .492 \\
\hline Total de escolas & 186.081 & Total de escolas & 65.475 \\
\hline Total de professores & 2.196 .397 & Total de professores & 960.899 \\
\hline Matrículas municipais & 23.103 .124 & Matrículas nas províncias & 10.424 .278 \\
\hline Matrículas estaduais & 15.946 .416 & Matrículas na CABA & \\
\hline Matrículas federais & 411.078 & & 707.611 \\
\hline
\end{tabular}

Fontes: Organizado pelos autores com base nos dados estatísticos disponibilizados no site do Ministério da Educación Nacional na Argentina e do Censo Escolar de 2018 no Brasil.

Nota: Os totais incluem a rede privada de ensino.

Pelos dados da Tabela, há um claro traço distintivo entre os dois países, que é o tamanho dos sistemas educacionais e quantitativos de matrículas. Mas há semelhanças, como a responsabilidade dos entes subnacionais, estados e municípios, no caso brasileiro, e províncias e CABA, no caso argentino, pela oferta e gestão do sistema. No Brasil, a fatia maior das matrículas está sob responsabilidade dos municípios e há uma quantidade muito pequena sob responsabilidade da União. Essas matrículas sob responsabilidade da União referem-se basicamente a algumas raras escolas de educação básica que ainda são mantidas pelo governo

${ }^{8}$ Segundo Anuário Brasileiro da Educação Básica de 2018 e Notas Estatísticas Censo Escolar 2018, produzidas pelo Instituto Nacional de Estudos e Pesquisas Educacionais e Ministério da Educação.

${ }^{9}$ Segundo dados do Informes Estadística Educativa do Ministério da Educación Nacional, com dados de 2015 2016.

${ }^{10}$ Segundo dados do Sistema Educativo Nacional, Informe Estadístico da Dirección Nacional de Información y Estadística Educativa do Ministério da Educación Nacional, com dados de 2015

${ }^{11}$ Segundo dados do Sistema Educativo Nacional, Informe Estadístico, Dirección Nacional de Información y Estadística Educativa do Ministerio da Educación Nacional, com dados de 2015.

RIAEE - Revista Ibero-Americana de Estudos em Educação, v. 14, n. esp. 3, p. 1688-1701, out., 2019. 
federal e, na sua maioria, são matrículas no ensino médio e no ensino técnico, ofertados em institutos federais de educação. Essa divisão de matrículas entre diferentes esferas de governo pode ser um traço cooperativo da federação em termos de responsabilidade pela provisão de educação básica. Na Argentina, pela inexistência de autonomia dos municípios como ente federado, a partir do texto constitucional nacional, os dados nacionais são computados pelo Ministério da Educação Nacional (MEN), dividindo as responsabilidades entre as províncias e a CABA, o que indica também que as matrículas da educação anterior ao ensino terciário estão sob responsabilidade de diferentes esferas de governo, mas, ao contrário do Brasil, não registram-se matrículas sob responsabilidade do governo central.

\section{Financiamento da educação no Brasil e na Argentina}

A opção pela organização federativa dos dois países analisados tem resultados não somente na distribuição de responsabilidades na oferta e gestão da educação entre os entes federados, mas também aparece na forma de repartição de competências e esforços para financiar os sistemas educacionais. No caso brasileiro, a CF/88 e a LDB/96 estabelecem um percentual mínimo da receita de impostos que cada ente federado deve aplicar no financiamento da educação, sendo $18 \%$ para a União e $25 \%$ para estados, Distrito Federal e municípios. Esse tipo de repartição não está presente no texto constitucional da Argentina, mas aparece algo semelhante na Ley de Financiamiento Educativo (ARGENTINA, 2006), quando estabelece que o Estado Nacional, as Províncias e a Cidade Autônoma de Buenos Aires, uma vez atingida a meta de gasto em educação, de valor equivalente a $6 \%$ do Produto Interno Bruto (PIB), destinem à educação, conjuntamente, pelo menos o mesmo patamar (6\% do PIB nacional).

No caso brasileiro, como fonte de recursos para o financiamento da educação, além dos percentuais mínimos da receita de impostos já citados (que constituem a principal fonte de financiamento da educação no país), há o Salário Educação, uma contribuição social cobrada tendo como base o total das remunerações pagas pelas empresas privadas, na proporção de 2,5\%. O salário educação é repartido em $10 \%$ (dez por cento) para o Fundo Nacional de Desenvolvimento da Educação (FNDE), que o aplica no financiamento de projetos, programas e ações da educação básica e os outros $90 \%$ (noventa por cento) são divididos em quotas, sendo $1 / 3$ (um terço) a quota federal e $2 / 3$ (dois terços) creditados mensalmente como quota estadual e municipal. Em linhas gerais, é um tributo arrecadado exclusivamente pela União e distribuído em parcelas entre todos os entes federativos, sendo que os recursos federais são usados para 
ações de assistência técnica e financeira aos municípios e estados. Cabe pontuar que, além destas fontes protegidas constitucionalmente, outros recursos orçamentários podem ser aplicados na educação, de acordo com as demandas, programas de governo e encargos de cada ente.

O elemento mais significativo da organização do financiamento da educação brasileira e que tem característica federativa é o Fundo de Manutenção e Desenvolvimento da Educação Básica e de Valorização dos Profissionais da Educação (FUNDEB), principal política de redistribuição de recursos e de cooperação federativa na educação. Trata-se, na verdade, de 26 fundos estaduais e um fundo do Distrito Federal, de natureza contábil e redistributiva, compostos por uma parte dos recursos da receita de impostos dos estados e dos municípios vinculada à manutenção e desenvolvimento do ensino (MDE) e por recursos complementares da União. A contribuição ao FUNDEB de cada estado e cada município é de $20 \%$ de parte dos impostos vinculados à educação, e a repartição dos recursos, feita no âmbito de cada estado, leva em conta as proporções de matrículas de cada ente. A complementação da União é a transferência de recursos a fundos estaduais cujos recursos próprios do governo estadual e das prefeituras não permitem atingir o valor mínimo nacional por aluno que, para o ano de 2019, é de R \$ 3.238,52; nove estados se beneficiam dessa complementação no ano de 2019: Alagoas, Amazonas, Bahia, Ceará, Maranhão, Pará, Paraíba, Pernambuco e Piauí. Em resumo, o FUNDEB é uma política de fundos contábeis de articulação federativa entre entes federados subnacionais (cada estado e respectivos municípios) e, quando necessário, há complementação do ente federado mais abrangente (União) aos fundos que necessitam de mais recursos. A União realiza também transferências obrigatórias de recursos (programas definidos em lei) e transferências voluntárias, cabendo-lhe estabelecer ações, critérios e condições para realização dessas transferências.

No caso argentino também há mecanimos de financiamento que expressam ou fortalecem a opção federativa do país. A Lei $\mathrm{n}^{\circ}$. 26.075, chamada Ley de Financiamiento Educativo (ARGENTINA, 2006), estabelece o aumento progressivo da aplicação de recursos em educação, ciência e tecnologia, tendo como meta atingir um gasto correspondente a $6 \%$ do PIB argentino em 2010, compromisso esse que deveria ser assumido pelos três entes federativos. Conforme previsão dessa Ley, dos recursos adicionais necessários ao cumprimento da meta, o compromisso do governo nacional representa uma proporção de $40 \%$, e o das províncias e Cidade Autônoma de Buenos Aires, 60\%; os primeiros deveriam ser aplicados nos órgãos dependentes do Estado nacional e apoio aos governos subnacionais, e os segundos 
prioritariamente na melhoria da remuneração docente, na hierarquização da carreira docente e na adequação da infraestrutura.

As províncias e a Cidade Autônoma de Bueno Aires, além dos recursos próprios assignados em seus orçamentos, devem contar com recursos transferidos pelo Estado nacional, chamados recursos coparticipables. O mecanismo legal mais importante que organiza essa situação é a Lei nº 23.548 de 1988, que trata da Coparticipación Federal de Recursos Fiscales (Argentina, 1988) e estabelece critérios para a distribuição primária e secundária de recursos do orçamento nacional. Esses recursos são repartidos de forma primária, de acordo com os $\operatorname{artigos~} 3^{\circ}, 4^{\circ}$ e $5^{\circ}$, na proporção de $42,34 \%$ para o governo nacional, 54,66\% entre as províncias, $2 \%$ para a recuperação das províncias de Buenos Aires, Neuquén e Santa Cruz e 1\% para um "Fondo de Aportes del Tesoro Nacional a las Províncias". A forma secundária de distribuição se dá a partir dos 54,66\%, distribuídos através de coeficientes fixos determinados em lei que, de acordo com Morado (2013), foram estabelecidos a partir do que foi recebido por cada província entre os anos de 1985 e 1987 (anos anteriores à aprovação da lei), decisão que resultou de negociações políticas daquele período. Dada a distribuição de recursos entre os entes federados e o papel do governo nacional nessa distribuição, os recursos coparticipáveis são de fundamental importância para o financiamento de políticas sociais para os entes subnacionais e, entre elas, as políticas educacionais.

Outra importante política que se relaciona com o financiamento diz respeito à aprovação, no ano de 2004, da prorrogação de vigência da Lei n ${ }^{\circ} .25 .053$ de 1988, que criou o Fondo Nacional de Incentivo Docente (FONID) (Argentina, 1988). Este Fundo buscou, através da criação de imposto sobre carros, motocicletas, embarcações e aeronaves, minimizar um problema crônico no país, a baixa remuneração docente. Em 2004 foi aprovada a Lei nº .25 .864 , a qual, entre outros elementos, prorrogou o FONID por mais cinco anos, estendendo sua vigência até o ano de 2009. Desde sua origem, foi estabelecido que, para ter direito aos recursos do FONID, as províncias e a CABA deveriam cumprir certas obrigações, como destinar os recursos exclusivamente a melhorar a remuneração docente, proibição de substituir os seus recursos próprios destinados à remuneração docente pelos recursos do fundo e desenvolver um programa de melhoria da administração e gestão educacional que otimizasse o uso dos recursos. Trata-se de uma política de âmbito nacional que estabelece relações federativas e auxilia, com recursos do governo nacional, o financiamento da educação básica e, nesse caso específico, o financiamento da remuneração dos professores.

Considerando a estrutura da educação básica nos dois países, a repartição de competências na oferta e gestão, bem como a relação federativa no financiamento, o gasto 
público em educação, seja o gasto total ou especificado de cada ente, tende a ser muito desigual entre os entes federativos, conforme ilustrado no Quadro 2.

Quadro 2 - Panorama geral dos gastos com educação na Argentina e no Brasil

\begin{tabular}{|c|c|c|}
\hline País & Perfil do gasto em educação & Valor/Percentual \\
\hline \multirow{6}{*}{ Brasil } & $\begin{array}{l}\text { Despesa total geral (local, regional e central) do } \\
\text { governo em educação em milhões de US\$ em PPP } \\
\text { (paridade de poder de compra) }\end{array}$ & US \$ 201249,04 \\
\hline & Gasto público em proporção ao PIB & $6,24 \%$ \\
\hline & \multicolumn{2}{|c|}{ Gasto público em educação por ente federativo } \\
\hline & União & $20,03 \%$ \\
\hline & Estados & $39,41 \%$ \\
\hline & Municípios & $40,06 \%$ \\
\hline \multirow{6}{*}{ Argentina } & Perfil do gasto em educação & Valor/Percentual \\
\hline & $\begin{array}{l}\text { Despesa total geral (local, regional e central) do } \\
\text { governo em educação em milhões de US } \$ \text { em PPP } \\
\text { (paridade de poder de compra) }\end{array}$ & US \$48 969,07 \\
\hline & Gasto público em proporção ao PIB & $5,57 \%$ \\
\hline & \multicolumn{2}{|c|}{ Gasto público em educação por ente federativo } \\
\hline & Nación & $30 \%$ \\
\hline & Províncias e Ciudad Autónoma de Buenos Aires & $70 \%$ \\
\hline
\end{tabular}

Fontes: Elaborado pelos autores com base nos dados do Unesco Institute for Statistics (UIS), Anuário Brasileiro da Educação Básica e a pesquisa de Bazen, Mezzadra e Rivas (2012).

Sobre esse Quadro, cabe explicar que os percentuais de despesa total geral do governo em educação em milhões de dólares foram retirados do banco de dados do Unesco Institute for Statistics (UIS), no qual a moeda nacional (Peso na Argentina e Real no Brasil) é convertida em dólares com paridade do poder de compra com o ano base de preços constantes 2014. Os dados do gasto público em proporção ao PIB também foram retirados do UIS e contabilizam o gasto total, incluindo todas as esferas de governo e todos os níveis ensino, inclusive educação superior. Em linhas gerais, o que o Quadro mostra, em valores monetários e percentuais, é o que já foi anteriormente pontuado: a maior participação dos entes subnacionais nas responsabilidades de financiamento da educação básica nos dois países.

\section{Considerações finais}

A opção pela organização federativa do Estado tem distintas motivações ao redor do mundo: culturais, linguísticas, geográficas ou mesmo políticas. No caso brasileiro, 
especificamente na área educacional, há um federalismo cooperativo inscrito no marco legal, pois as responsabilidades na oferta e financiamento da educação são compartilhadas entre os entes federados, com prioridades de cada qual; também se pode adjetivar de federalismo centrífugo, já que distribui poder aos entes subnacionais, consagrando um sistema descentralizado. No caso argentino ocorre a descentralização e divisão de responsabilidades entre os entes federados, cabendo ao governo nacional a organização do financiamento da educação e aos outros entes a gestão, o financiamento e a oferta da educação. A Constituição argentina, em seu artigo 128, define a relação entre os entes federados como "[...] de un federalismo cooperativo y de concertación (y, por tanto, no competitivo)." (ARGENTINA, 1994). Essa distribuição de poder em uma federação ocorre a partir de mecanismos jurídicos de distribuição de responsabilidades e reafirmação de autonomia dos entes federativos, não confundindo autonomia com soberania, já que todos os entes federados estão sob a égide da mesma Constituição soberana.

No que diz respeito ao financiamento da educação básica, nos dois países há mecanismos de financiamento que articulam todos os entes federados, seja via coparticipação federal de impostos, como na Argentina, ou via política de fundos, como no caso brasileiro. Fica claro também, pelos documentos legais analisados e pelos dados de financiamento apresentados, que a articulação federativa no financiamento da educação, em ambos os casos, conta com importante papel do governo nacional, distribuindo recursos ou atuando de forma complementar. Ainda assim, de acordo com os dados do Quadro 2, fica claro que, mesmo com mecanismos federativos na distribuição de responsabilidades e no financiamento, a maior parte do financiamento da educação básica está a cargo dos entes subnacionais; estados e municípios, no caso do Brasil, e CABA e províncias, no caso da Argentina.

\section{REFERÊNCIAS}

ABRUCCIO. Luiz Fernando. A dinâmica federativa da educação brasileira: diagnóstico e propostas de aperfeiçoamento. In: OLIVEIRA. Romualdo Portela de; SANTANA. Wagner. Educação e federalismo no Brasil: combater desigualdades, garantir a diversidade. Brasília: Editora da UNESCO, 2010

ARGENTINA. Constitución de la Nación Argentina. Disponível em: https://www.casarosada.gob.ar/images/stories/constitucion-nacional-argentina.pdf. Acesso em 30 nov 2018.

ARGENTINA. Ley $\mathbf{n}^{\circ} \mathbf{2 6 . 2 0 6}$ ley de educación nacional. Disponível em: https://www.argentina.gob.ar/sites/default/files/ley-de-educ-nac-58ac89392ea4c.pdf. Acesso em: 27 nov 2018. 
ARGENTINA. Ley no 23548 de 22 janeiro de 1988. Coparticipación Federal de Recursos Fiscales. Establécese el Régimen Transitorio de Distribución entre la Nación y las Provincias, a partir del $1^{\circ}$ de enero de 1988. Disponível em: http://servicios.infoleg.gob.ar/infolegInternet/anexos/20000-24999/21108/texact.htm. Acesso em: 15 jul de 2018.

ARGENTINA. Ministerio de educación y deportes. Sistema educativo Nacional: informe estadístico. Edición enero de 2017. Buenos Aires. 2017. Disponível em: https://www.fundacionluminis.org.ar/biblioteca/sistema-educativo-nacional-informeestadistico. Acesso em: 06 jun 2019.

ARGENTINA. Ministerio de Educación, Cultura, Ciencia y Tecnología. Gasto en educación por nivel de gobierno. Buenos Aires. 2018. Disponível em:

https://www.argentina.gob.ar/educacion/planeamiento/gasto-en-educacion-por-nivel-y-porobjeto. Acesso em: 07 jun 2019.

BAZÁN, Victor. El Federalismo Argentino: situación actual, cuestiones conflictivas y perspectivas. Estudios Constitucionales, Año 11, № 1, p. 37 - 88, 2013. Disponível em: https://scielo.conicyt.cl/scielo.php?script=sci_arttext\&pid=S0718-52002013000100003. Acesso em: $02 \mathrm{dez} 2018$.

BOBBIO, Norberto; MATTEUCCI, Nicola; PASQUINO, Gianfranco. Dicionário de Política. 13ª ed. Brasília: Editora UNB, 2010.

BRASIL. Constituição da República Federativa do Brasil de 1988. Disponível em: http://www.planalto.gov.br/ccivil_03/Constituicao/Constituicao.htm. Acesso em: $01 \mathrm{dez}$ 2018.

BRASIL. Lei de Diretrizes e Bases da Educação Nacional. 1996. Disponível em: http://www.planalto.gov.br/ccivil_03/LEIS/L9394.htm. Acesso em: 01 dez 2018.

BRASIL. Instituto Nacional de Estudos e Pesquisas Educacionais Anísio Teixeira. Notas Estatísticas do Censo Escolar de 2018. Brasília, 2018. Disponível em:

http://download.inep.gov.br/educacao_basica/censo_escolar/notas_estatisticas/2018/notas_est atisticas_censo_escolar_2018.pdf.Acesso em: 08 jun 2019.

CENTRO DE IMPLEMENTACIÓN DE POLÍTICAS PÚBLICAS PARA LA EQUIDAD Y EÇ CRECIMIENTO. Monitoreo de la Ley de Financiamiento Educativo: informe final. Buenos Aires. 2013. Disponível em: https://www.cippec.org/wpcontent/uploads/2013/09/Bezem2c-Mezzadra-y-Rivas-Informe-Final-Monitoreo.pdf. Acesso em: 07 jun 2019.

CENTRO DE IMPLEMENTACIÓN DE POLÍTICAS PÚBLICAS PARA LA EQUIDAD Y EÇ CRECIMIENTO. Documento de Trabajo $\mathbf{N}^{\circ} \mathbf{1 6 2}$. El financiamiento educativo en Argentina. Buenos Aires. 2018. Disponível em: https://www.cippec.org/wpcontent/uploads/2018/02/DT-162-EDU-Financiamiento-educativo_2018-01-VF.pdf. Acesso em: 07 jun 2019. 
CONSEJO NACIONAL DE CORDINACIÓN DE POLÍTICAS SOCIALES. EI gasto público social y el presupuesto de 2018. Buenos Aires. 2018. Disponível em:

https://www.argentina.gob.ar/sites/default/files/politicassociales-publicaciones-informe-gastosocial-2018.pdf. Acesso em: 08 jun 2019.

FARENZENA, Nalu et al. Políticas de financiamento público da educação no Uruguai, Argentina e Brasil num período de governos progressistas. Relatório de Pesquisa. Porto Alegre, UFRGS, 2018 (texto digitado).

MARTINS. Paulo de Sena. FUNDEB, federalismo e regime de colaboração. Campinas: Editores Associados, 2011.

MORADO. Natalia. Federalismo Fiscal em Argentina: regímenes de transferências del gobierno central a las províncias. Mendonza. 2013. Disponível em:

http://bdigital.uncu.edu.ar/objetos_digitales/6721/morado-tesisfce.pdf. Acesso em 30 maio 2019.

OLIVEIRA, Fabrício Augusto. Teorias de Federação e do Federalismo Fiscal: o caso brasileiro. 2007. Disponível em: http://www.eg.fjp.mg.gov.br/index.php/docman/publicacoes2007/84-teorias-da-federacao-e-do-federalismo-fiscal-o-caso-brasileiro/file. Acesso em: 25 nov 2018.

OLIVEIRA. Romualdo Portela de; SANTANA. Wagner. Educação e federalismo no Brasil: combater desigualdades, garantir a diversidade. Brasília: Editora da UNESCO, 2010.

TODOS PELA EDUCAÇÃO. Anuário Brasileiro da Educação Básica 2018. São Paulo: Editora Moderna. 2018. Disponível em: https://todospelaeducacao.org.br/_uploads/20180824Anuario_Educacao_2018_atualizado_WEB.pdf?utm_source=conteudoSite. Acesso em: 08 jun 2019.

UNESCO, Institute for Statistic. Gastos do governo com educação como porcentagem do PIB. Nova York. 2017. Disponível em: http://data.uis.unesco.org/\#. Acesso em: 08 jun 2019.

VENTURA. Sofia. Il federalismo: il potere diviso tra centro e periferia. Bologna: Società editrice il Mulino, 2002.

\section{Como referenciar este artigo}

TORMES, D. D. da S.; FARENZENA, N. Relações federativas no financiamento da educação no Brasil e na Argentina. Revista Ibero-Americana de Estudos em Educação, Araraquara, v. 14, n. esp. 3, p. 1688-1701, out., 2019. e-ISSN: 1982-5587. DOI: 10.21723/riaee.v14iesp.3.12754

Submetido em: 25/03/2019

Revisões requeridas: 20/04/2019

Aceito em: 10/05/2019

Publicado em: 30/08/2019 